\title{
Cell wall composition and in vitro fermentation characteristics of maize
}

\author{
HJP Marvin, CF Krechting, EN van Loo, CHA Snijders, O Dolstra \\ DLO-Centre for Plant Breeding and Reproduction Research (CPRO-DLO), Droevendaalsesteeg 1 , \\ PO Box 16, 6700 AA Wageningen, The Netherlands
}

The extent of digestibility of organic matter (OMD) has been the most important forage quality characteristic. Consequently, maize breeders have put much emphasis on genetic improvement of OMD. However, recent insights have shown that in order to optimize ruminant utilization of nutrients from their feed, rate of digestion and fermentation profile [VFA (volatile fatty acids) and microbial biomass production] should also be taken into account.

To study the genetic control of biochemical factors that determine the fermentation characteristics of the stalk-cell walls of maize, we have generated a series of homozygous recombinant inbred lines of maize (RILs). The stalk fraction of 25 different RILs was analyzed for extent of digestibility, i.e. organic matter (OMD) and cell wall (CWD) digestibility according to Dolstra et al (1993, Euphytica, 65, 187-194), and for the amount of VFAs formed after a 48 hours incubation in rumen fluid in vitro. In addition, the cell wall composition of the stalk fraction was determined. The following cell wall constituents were quantified: neutral and acid detergent fiber (NDF and $A D F$, respectively), cellulose (CEL), hemicellulose (HEM), permanganate lignin (pLIG) and total phenolics (tPHEN).

The performance of RILs for stalk-OMD and stalk-CWD ranged from $63-82 \%$ and 45 -
$66 \%$, respectively. The amount of individual VFAs present in the fluid after incubation in rumen fluid differed greatly among the RILs. The following range of concentrations was found in this set of RILs : $29-52 \mathrm{mM}$ for acetate, $12-25 \mathrm{mM}$ for propionate, $2.3-4.3$ $\mathrm{mM}$ for butyrate, and $1.6-2.6 \mathrm{mM}$ for valerate. The observed ratio acetate/propionate ranged from 1.87 - 2.59 .

Chemical characterization of the cell walls revealed large differences between the RILs (NDF, 435 - $685 \mathrm{~g} / \mathrm{kg} \mathrm{DM} \mathrm{;} \mathrm{ADF,} 253-411 \mathrm{~g} / \mathrm{kg}$ DM ; CEL, 199 - $333 \mathrm{~g} / \mathrm{kg}$ DM ; HEM, 182 $273 \mathrm{~g} / \mathrm{kg}$ DM ; pLIG, $44 \cdot 74 \mathrm{~g} / \mathrm{kg}$ DM and tPHEN, 91 - $116 \mathrm{~g} / \mathrm{kg} \mathrm{DM).}$

Correlation studies showed high positive correlations between the VFAs acetate and respectively propionate $(r=+0.93)$, butyrate $(r=+0.94)$ and valerate $(r=+0.97)$. The amounts of acetate and propionate were related to OMD $(r=+0.74$ and +0.85 , respectively) and to CWD ( $r=+0.66$ and +0.64 ). Propionate was also highly negatively correlated with NDF, ADF, CEL and $\mathrm{pLIG}(\mathrm{r}=-0.82,-0.80,-0.75$ and -0.84 , respectively).

In conclusion, this study shows that plant breeding can generate variation in cell wall fermentation characteristics of maize stalks which may be used to manipulate VFA-profiles. 